\title{
Clinical Factors, Disease Parameters, and Molecular Therapies Affecting Osseointegration of Orthopedic Implants
}

\author{
Hilal Maradit Kremers ${ }^{1,2}$ • Eric A. Lewallen ${ }^{1}$ Andre J. van Wijnen ${ }^{1}$. \\ David G. Lewallen ${ }^{1}$
}

Published online: 29 June 2016

(C) Springer International Publishing AG 2016

\begin{abstract}
Total hip and knee arthroplasty are effective interventions for management of end-stage arthritis. Indeed, about seven million Americans are currently living with artificial hip and knee joints. The majority of these individuals, however, will outlive their implants and require revision surgeries, mostly due to poor implant osseointegration and aseptic loosening. Revisions are potentially avoidable with better management of patient-related risk factors that affect the osseointegration of orthopedic implants. In this review, we summarize the published clinical literature on the role of demographics, biologic factors, comorbidities, medications, and aseptic loosening risk. We focus on several systemic and local factors that are particularly relevant to implant osseointegration. Examples include physiological and molecular processes that are linked to hyperglycemia, oxidative stress, metabolic syndrome, and dyslipidemia. We discuss how orthopedic implant osseointegration can be affected by a number of molecular therapies that are antiresorptive or bone anabolic (i.e., calcium, vitamin D, bisphosphonates, calcitonin, strontium, hormone replacement therapy, selective estrogen receptor modulators).
\end{abstract}

Keywords Arthroplasty · Osseointegration · Aseptic loosening

This article is part of the Topical Collection on Stem/Progenitor Cells Biology and Regeneration

Hilal Maradit Kremers

maradit@mayo.edu

1 Department of Orthopedic Surgery, Mayo Clinic, 200 First St SW, Rochester, MN 55905, USA

2 Department of Health Sciences Research, Mayo Clinic, 200 First St SW, Rochester, MN 55905, USA

\section{Introduction}

Total hip (THA) and total knee (TKA) arthroplasties are effective and relatively safe procedures for management of endstage arthritis of the hip and knee joints. The incidence of these procedures has increased almost exponentially in recent years with over one million procedures performed annually in the USA [1]. As a result of the high incidence and the long life expectancy following surgery, there are currently seven million individuals (about $2 \%$ of the US population) with a history of THA and/or TKA [2•]. Unfortunately, a substantial proportion of these individuals will outlive their implants and require expensive revision surgeries. Although revision is considered an avoidable outcome, relatively little is known about factors that influence the risk of revisions in THA and TKA. The etiology of revisions is multifactorial including patient, implant, surgical, and healthcare delivery factors. The causal contribution of each of these factors likely differs during the lifetime of an arthroplasty patient. For example, surgical and healthcare delivery factors have a significant influence on the short-term risk of complications, whereas patient and implant factors can have a large influence on the osseointegration potential of the implants and the subsequent risk of revisions, particularly due to aseptic loosening.

This review paper provides a summary of the published clinical literature on patient-related risk factors, diseases, and molecular therapies that may affect osseointegration of orthopedic implants in THA and TKA patients. We focus almost exclusively on the potential biological and molecular effects of the patient-related risk factors and deliberately exclude implant, surgical, and healthcare delivery factors. Readers are also encouraged to refer to other comprehensive reviews and manuscripts on this topic $[3,4 \cdot, 5]$. Of note, the evidence for each of the patient-related risk factors is variable. Some are studied extensively in large clinical studies, whereas others are 
only studied experimentally in vitro and in vivo. We nevertheless provide a critical discussion of selected disease and treatment factors of interest based on biological plausibility, basic science, and/or clinical evidence.

\section{Demographic Factors}

Age Age is a well-known risk factor for revision in both THA and TKA [3, 6-9]. The majority of large, registry-based cohort studies reported a linear increase in the risk of revision with decreasing age. The age effect is not simply due to comorbid joint pathologies in younger patients and persisted when cohorts were restricted to osteoarthritis patients. For example, in one of earliest studies reporting on the prognosis of THA in Sweden, patients younger than 55 years of age at the time of THA surgery had the highest risk of revisions for aseptic loosening followed by decreasing order in the 55-64, 65-74, and $>75$ years olds [10]. In another large cohort of more than 30,000 TKA surgeries from Finland, the risk of aseptic revisions was almost 5 -fold higher among patients younger than 55 years as compared to patients older than 65 years [11]. In studies from our group, younger THA and TKA patients experienced a higher risk of revision irrespective of implant type [12-14]. Although the increased risk of revision in younger patients has been almost entirely attributed to higher activity levels and higher loading on the joints, it is unknown whether other age-related factors affect bone quality and, in turn, contribute to the excess risk of revisions in young patients. We believe that further studies are warranted to better understand the age effect, such as studies of periprosthetic bone remodeling [15] and in vivo and in vitro studies of the potential role of bone mineral density, bone mineral content, peak bone mass, and bone turnover markers on osseointegration and risk of aseptic loosening in THA and TKA. Because tissue regeneration around implants depends on endogenous mesenchymal stem cells, it will be informative to assess whether the molecular properties of stem cells and their ability to support periimplant bone formation are altered.

Sex Sex is another well-studied but often ignored risk factor for revision in both THA and TKA. In the majority of studies, men have at least a 1.5- to 2-fold higher risk of aseptic revisions than women $[3,6,13,14,16]$. Yet, this is not a universal finding. For example, in our recent follow-up analysis of revision THA, women have a significantly higher risk of repeat revision for aseptic loosening than men [12]. Similarly, within the Kaiser Permanente Joint Registry, women have a higher risk of aseptic THA revision than men, whereas there was no difference between men and women in the risk of aseptic TKA revision $[8,17]$. These differences across studies and joint type suggest that more research is justified to better understand the sex differences in osseointegration potential of implants. Sex differences cannot be solely attributed to anatomical, kinematic, and implant-type differences between men and women. It remains to be seen how anatomical and mechanical differences influence the risk of different failure mechanisms on different joints, and whether hormonal factors across the lifespan may play a role in meditating osseointegration, and potential age-related risk of aseptic loosening. Future studies are warranted in this area to understand the contributions of age, menopausal status, and age at menopause to the risk of aseptic loosening and revision in women. Furthermore, evidence from osteoporosis research indicates that, although estrogen deficiency is traditionally viewed as the main contributor of bone loss [18], other estrogenindependent factors also affect bone quality and some of these are more relevant to the solid fixation of implants during THA and TKA, e.g., mechanical loading.

Race Despite the recognition of racial and ethnic differences in arthritis disease severity and access to THA and TKA surgery [19, 20], surprisingly, little is known about variation in the risk of complications and revisions in different racial groups. In two recent studies from the Kaiser Permanente Registry, Hispanic and Asian Americans had a lower risk of aseptic revisions, whereas African Americans had a higher risk of aseptic revisions in TKA only [7, 8]. Presumably, the etiology of racial and ethnic differences in outcomes is multifactorial and includes healthcare delivery factors, insurance status, and patient preferences as well as interracial differences in lifestyle factors (i.e., nutrition, body mass index, physician activity). Yet, there is also ample evidence from other diseases about the potential role of biological and genetic factors. For example, African American women have stronger bones and have a lower risk for osteoporotic fracture than White women [21]. It remains to be seen whether stronger bones in African Americans also translate into better osseointegration potential and lower risk of revision, independent of the influence of other factors. Therefore, studies of racial differences can provide clues about the etiology of osseointegration in arthroplasty. In this context, ethnically prevalent genetic variations, as well as epigenetic modifications associated with lifestyle and other environmental factor exposure changes, may contribute to new bone formation around implants.

Obesity Obesity is the main risk factor for osteoarthritis, and at least half of the arthroplasty patients are obese with a body mass index higher than $30 \mathrm{~kg} / \mathrm{m}^{2}$ [22]. Obesity is associated with several adverse outcomes in THA and TKA. Yet, evidence is conflicting in terms of the risk of aseptic loosening [23-27]. This is, in part, due to statistical methodology and information loss through restriction of body mass index (BMI) categories and, in part, by inability to account for activity levels in the majority of studies. In one pooled analysis and two recent studies [26-28], the risk of aseptic loosening was about 2-fold 
higher among individuals with a BMI above $35 \mathrm{~kg} / \mathrm{m}^{2}$. Supported by basic science evidence, this has been attributed to increased mechanical stress and more frequent limb malalignment in obese patients. These findings were not corroborated in other studies $[7,8,24]$. For example, in a large cohort of THA patients from our institution, increasing BMI was not associated with the risk of mechanical failure of the implant or aseptic loosening, but BMI correlated negatively with the risk of revision for bearing surface wear [24]. It has been suggested that obesity-associated stress on implant interfaces may be offset by lower activity levels in very obese patients. Yet, the potential contribution of metabolic effects of the fat mass at different body sites (e.g., visceral versus subcutaneous) on osseointegration of the implants is currently unknown. At the population level, although obesity is traditionally associated with higher bone mineral density and a lower risk of fractures, emerging evidence suggests that this is not universally true [29]. It is unknown whether sex, age, bone mineral density, and the severity or the type of obesity could modulate osseointegration and the risk of aseptic loosening in THA and TKA. Evidence from bariatric surgery studies in arthroplasty patients is also particularly relevant in this regard.

Smoking and Alcohol Consumption Smoking and alcohol consumption are two important behavioral risk factors for a number of adverse outcomes following surgery, including THA and TKA. Excessive amounts can theoretically increase the risk of aseptic loosening due to delayed bone healing and bone regeneration [30, 31]. In a pooled analysis of THA studies, smokers had a 3 -fold higher risk of aseptic loosening than non-smokers [32]. Yet, in a recent study by our group, smoking was not associated with the risk of aseptic revisions, whereas alcohol use was associated with a significantly lower risk of revision [33]. Heavy alcohol use was associated with dislocation but not aseptic loosening in two earlier studies [34, 35]. The reasons for the discrepant findings are unknown but potentially include methodological differences, because risk factor data collection is typically limited to the immediate perioperative period. More studies are warranted that examine risk of aseptic revisions with longitudinal risk factor data collection. This is important since both smoking and alcohol can theoretically affect osseointegration potential through their detrimental effects on bone mineral density $[36,37]$.

\section{Surgical Indications}

Although the majority of patients undergoing THA and TKA are degenerative osteoarthritis patients, about $10-15 \%$ have other underlying diseases and operative indications, including post-traumatic degenerative arthritis, as well as rheumatoid arthritis and other joint-related inflammatory processes, avascular necrosis (steroid-induced, post-traumatic, or idiopathic), congenital hip conditions (developmental dysplasia), and neoplasias. Rheumatoid arthritis is perhaps the best studied condition. THA patients with inflammatory arthritis had a significantly lower risk of aseptic loosening than osteoarthritis patients [16]. In contrast, THA patients with hip dysplasia had twice the risk of aseptic loosening than osteoarthritis patients. In more recent studies, patients with rheumatoid arthritis experience a higher risk of revision due to infection and dislocation, but the long-term risk of aseptic loosening is similar to patients with osteoarthritis [6,38-41]. There are no data on the long-term revision risk in patients with other forms of inflammatory arthritis. Developmental dysplasia of the hip is associated with poor bone stock and various technical problems resulting in a higher risk of aseptic loosening in THA [42]. Similarly, THA for femoral neck fractures is associated with a higher risk of aseptic loosening [43]. TKA following open reduction and internal fixation of a tibial plateau fracture presents similar technical challenges but does not increase the risk of aseptic loosening [44]. Even though evidence for a direct impact of skeletal degeneration and inflammatory processes on patient risk remains inconclusive, it is likely that the physiological condition of the patient will modify the cellular and molecular processes that guide skeletal tissue repair around the implant after surgery.

\section{Comorbidities}

Osteoporosis Osteoporosis is the most common condition affecting bone quality in the elderly. It affects about one third of women and one fifth of men aged 50 years and older in the USA [45]. Although osteoarthritis and osteoporosis are traditionally viewed to have an inverse relationship [46॰], contemporary understanding of both diseases recognizes different disease phenotypes, including the presence of osteoporotic, erosive, and bone-forming osteoarthritis phenotypes [46•, 47-49]. Indeed, several studies found a high prevalence of osteoporosis in THA and TKA patients [50-53]. Yet, little is known about the effects of low bone mineral density on arthroplasty outcomes and the potential beneficial or adverse effects of antiresorptive (i.e., bisphosphonates) and bone anabolic osteoporosis medications. So far, studies in osteoporosis patients are relatively small and focused mostly on implant fixation with cemented versus uncemented prostheses or implant migration [54]. There are no studies examining the interactions of bone mineral density, BMI, and other factors (e.g., inflammation) to modify arthroplasty outcomes. Consequently, at present, there is little emphasis on the evaluation of bone quality in arthroplasty candidates. This is unfortunate because bone mineral density and bone turnover markers may offer potential for risk stratification [55]. As summarized below, there is increasing in vivo and in vitro evidence for the potential beneficial effects of bisphosphonates in arthroplasty patients. 
Diabetes Mellitus Emerging evidence in the last decade suggests that diabetes mellitus is a risk factor for osteoarthritis, leading to the concept of a "diabetes-induced osteoarthritis" $[56,57,58 \cdot, 59,60]$. In vivo evidence suggesting potential role of diabetes control in reducing the severity of osteoarthritis led to studies that specifically examine the potential protective role of antidiabetic drugs in delaying osteoarthritis progression and the risk of arthroplasty [61]. Despite promising in vivo data, clinical studies to date are negative. It remains to be seen whether insulin and/or other antidiabetic drugs delay the progression and severity of osteoarthritis and delay the need for joint arthroplasty. In contrast, individuals with type 2 diabetes may have an increased fracture risk, despite normal bone mineral density [62]. The mechanisms underlying bone fragility associated with diabetes are not completely understood but include effects of obesity, hyperglycemia, oxidative stress, and accumulation of advanced glycation end products, which lead to altered bone metabolism, structure, and strength [63, 64]. In THA and TKA, diabetes mellitus strongly affects functional and perioperative clinical outcomes [65-70], but long-term effects on the risk of aseptic revisions are mostly negative. In two large studies from the Scandinavian Arthroplasty registries, diabetes mellitus was associated with an increased risk for revision due to deep infection but not aseptic loosening [71, 72]. In the Kaiser Permanente Registry, presence of diabetes was a risk factor for aseptic loosening in TKA but not in THA [7, 8]. In a recent study from our institution [73], insulin-dependent diabetes was associated with a 2-fold higher risk of revision in TKA, but not necessarily due to aseptic loosening. Collectively, even though there is no clear clinical evidence yet, conceptually, it is quite plausible that diabetes and hyperglycemia have systemic and/or local effects on healing of the bone-implant interface [58•].

Metabolic Syndrome and Dyslipidemia There is emerging evidence suggesting that dyslipidemia, and particularly high oxidized LDL-cholesterol, has a role in osteoarthritis pathology independent of obesity and mechanical overload [74-77]. The hip, knee, and hand joints may have different susceptibility to metabolic and non-metabolic factors [78, 79]. In fact, osteoarthritis is currently recognized not as a single entity, but a variety of conditions with distinct genetic, developmental, metabolic, and traumatic causes that converge on a common disease phenotype $[47,58 \bullet$. Unfortunately, despite the high prevalence of obesity, metabolic syndrome, and dyslipidemia in the arthroplasty population and higher risk of associated complications [80], it is unknown whether the presence of a metabolic syndrome affects osseointegration and aseptic loosening risk in THA and TKA. If this is the case, lowering cholesterol levels or local inflammation systematically or locally can be an effective treatment strategy for improving osseointegration. Progress in the bone and fat tissue connection is remarkable [81] with demonstration of several systemic and local interactions that are particularly relevant in implant osseointegration research.

Collectively, our review of the clinical literature indicates that, first, indirect evidence from osteoporosis and obesity studies provides etiological clues about the potential effects of comorbidities on osseointegration potential of implants. Second, recognizing the heterogeneous nature of osteoarthritis, the main underlying indication for THA and TKA, future clinical studies should distinguish osteoarthritis phenotypes by reporting outcomes separately in men and women, patients with or without history of trauma, athletes, and non-athletes, as well as obese and non-obese patients. Figure 1 broadly illustrates the emerging paradigms in pathogenesis of arthritis and how osseointegration potential and prognosis likely vary in different osteoarthritis phenotypes. A range of systemic and local factors affect osseointegration, and the relative contribution and host response likely differ in each osteoarthritis phenotype. Third, a number of other common diseases of aging and their treatments are also of interest, including hypertension, renal disease, various forms of cardiovascular disease, heart failure, depression, Parkinson's disease, and Alzheimer's disease [72]. Yet, at the time of this review, evidence is limited for inclusion in this review. Finally, both direct and indirect evidence for the role of genetic and epigenetic risk factors on age-related changes in bone metabolism and osteoarthritis may offer solutions for improving osseointegration [82-85].

\section{Medications}

The medication classes of interest within the context of orthopedic implant osseointegration are antiresorptive drugs (i.e., calcium, vitamin D, bisphosphonates, calcitonin, strontium, hormone replacement therapy, selective estrogen receptor modulators), bone anabolic drugs (i.e., parathyroid hormone, teriparatide), and other drugs for comorbidities that are common in elderly patients.

Calcium and Vitamin D Calcium and vitamin D are essential for bone development, skeletal remodeling, and fracture repair. Yet, there is no evidence to support the efficacy of vitamin D supplementation in fracture prevention, and screening and supplementation are not recommended among asymptomatic adults. Similarly, vitamin D supplementation has no benefit in knee osteoarthritis patients [86]. Vitamin D deficiency is common in arthroplasty patients [52], but uncertainty remains concerning whether vitamin $\mathrm{D}$ supplementation may help with osseointegration in THA and TKA patients, particularly among those with low bone mineral density and/ or low vitamin D levels.

Bisphosphonates Bisphosphonates are the most commonly used antiresorptive drugs for the treatment of osteoporosis. 
Fig. 1 Etiological paradigm of osseointegration in total joint arthroplasty

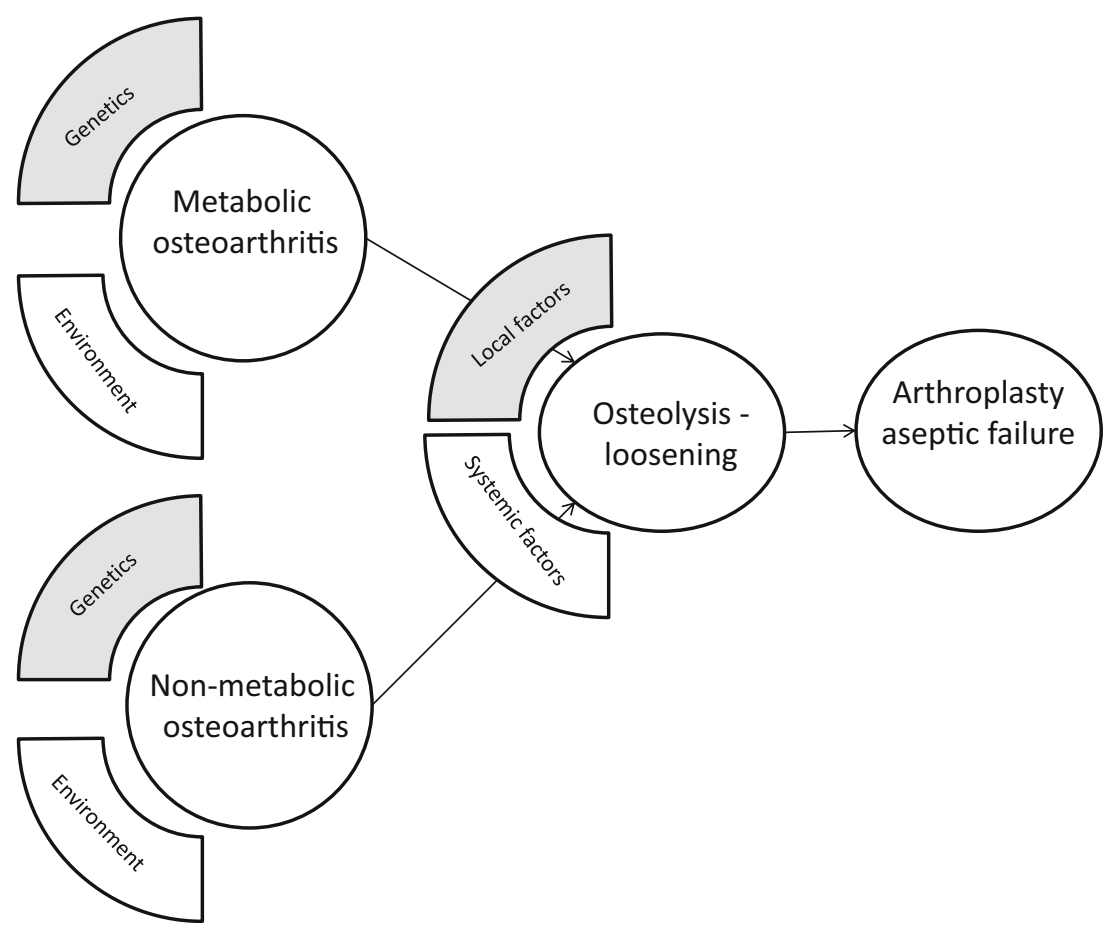

They are also studied extensively in animal models, in vitro experiments, and clinical studies to improve the osseointegration of implants in THA and TKA patients [87]. Clinical evidence strongly supports bisphosphonate effects on both the intermediate (i.e., periprosthetic bone loss and implant migration) and clinical outcomes. Systemic, long-term use of bisphosphonates significantly reduces the risk of revision in arthroplasty patients [87-93, 94•, 95-97]. For example, in a meta-analysis of four studies, THA and TKA patients who used bisphosphonates for a long period had a $50 \%$ reduction in their risk of implant revision [94•]. Yet, the optimal timing for initiation of bisphosphonates in arthroplasty patients is unknown, especially considering the periprosthetic changes during the early months. It is possible that an early initiation may, in fact, delay osseointegration [98]. It is also unclear whether local administration is more efficacious than systemic use, particularly in patients with normal bone mineral density.

Calcitonin Calcitonin is another antiresorptive agent that inhibits osteoclast formation and activity. Data supporting the possible effects of calcitonin on osseointegration has been collected from animal studies [99], although the homeostatic balance between osteoblasts and osteoclasts in bone-forming tissues needs to be further investigated in human subjects.

Strontium Strontium has both antiresorptive and bone anabolic properties and affects fracture healing differently in normal and osteoporotic bones. Experimentally, it improves osseointegration, but clinical studies are lacking.
Hormone Replacement Therapy Hormone replacement therapy has antiresorptive effects and has been the cornerstone of prevention of postmenopausal bone loss and osteoporosisrelated fractures until adverse cardiovascular effects were recognized in late 1990s. Although the prevalence of hormone replacement therapy is currently low, its use was high during the 1980s and 1990s, and investigators observed a $40 \%$ reduction in the risk of revision among patients who continued use for at least 6 months after THA-TKA surgery [100]. This finding provides further support for potential adverse effects of estrogen deficiency and possible beneficial role of antiresorptive drugs on the osseointegration of orthopedic implants. It remains to be seen whether the local enhancement of implants with estrogen can improve osseointegration, particularly in estrogen-deficiency-related osteoarthritis.

Selective Estrogen Receptor Modulators Selective estrogen receptor modulators do not have the steroid structure of estrogen but have a tertiary structure that allows binding to the estrogen receptors to exert agonistic effects on the bone. The effects of selective estrogen receptor modulators on bone mineral density may be less than bisphosphonates [101]. So far, there are no animal or clinical studies that relate selective estrogen receptor modulators to the outcomes of THA and TKA.

Vitamin C Vitamin C is a micronutrient found in fruits and vegetables and has been shown to mediate osteoclastogenesis and osteoblastogenesis resulting in better bone health [102, 103]. Studies reporting on associations between vitamin $C$ intake and fracture risk are promising, but there are no in vivo 
or in vitro studies on the possible effects of vitamin $\mathrm{C}$ in arthroplasty patients.

NSAIDS and Opioids NSAIDS and opioids play an important role in pain management both before and after THA and TKA. Several studies, mostly in fracture patients, suggest that NSAIDs and opioids interfere with bone growth [104, 105]. Yet, so far, studies in THA and TKA are few and conflicting with respect to osseointegration and the subsequent risk of aseptic loosening [106-109].

Insulin Insulin is generally regarded as a bone anabolic agent $[60,110]$. Although some studies showed an excess risk of fracture in insulin users, this is likely due to insulin use serving as a marker of diabetes severity rather than direct effects of insulin on the bone. Among other oral hypoglycemic agents, data for metformin is neutral, whereas thiazolidinediones are associated with a doubling of fracture risk in women [111]. Clinical studies on the effects of insulin and oral hypoglycemic agents are lacking in THA and TKA patients.

Statins Statins have previously been shown to be associated with higher bone mineral density and reduced fracture risk in a number of observational studies [112-114], but these findings are not corroborated in clinical trials $[115,116]$. The discordance between observational studies and randomized trials is explained by selection bias, confounding by indication, or a "healthy-user" phenomenon [117]. Systemically administered statins are associated with a reduced risk of aseptic revision and osteolysis in at least two THA studies [118, 119]. Yet, evidence from local delivery of statins on orthopedic implants is so far inconclusive. It remains to be seen whether long-term oral statin therapy, at least in selected patients, or local application can improve osseointegration and reduce the risk of aseptic loosening.

Disease-Modifying Drugs Disease-modifying drugs (DMARDs) or biologic DMARDs are of significant interest in the context of osseointegration of implants due to the high prevalence of arthroplasty procedures in patients with rheumatoid arthritis [120]. There is evidence to suggest that extensive use of biologic DMARDs led to a decline in arthroplasty rates in some joints. Controversy exists on how best to manage DMARDS during the perioperative period due to a higher risk of infections. Regarding the effects of various DMARDs on osseointegration potential, there are theoretical grounds that they can reduce the risk of aseptic loosening by suppressing the particle-mediated chronic inflammation at the boneimplant interface. This hypothesis is, in part, supported by a large cohort study from Finland that showed a slightly reduced risk of revision in patients using biologics when compared with patients on traditional DMARDs [121]. Further studies are warranted about the potential effects of commonly used DMARDs.
Antidepressants Antidepressants, and particularly selective serotonin reuptake inhibitors (SSRI), can have negative effects on the bone and increase the risk of fractures [122, 123]. Depression is also one of the strongest risk factors for revision in arthroplasty patients [72]. However, it is unknown whether the risk is mediated primarily by the disease pathology or secondarily by antidepressant medications.

Thiazide Diuretics Thiazide diuretics reduce renal calcium excretion, regulate intracellular calcium, inhibit osteoclastic bone resorption, and can therefore affect bone metabolism in an osteo-protective manner. In contrast, loop diuretics increase renal calcium excretion and have opposite effects on the bone. Empirical data are consistent with theoretical mechanisms and suggest that thiazide diuretics are associated with a reduced risk of fractures in a dose-dependent manner, whereas loop diuretics are potentially harmful to the bone [124, 125]. There is only one clinical report on arthroplasty patients [126]. In a nationwide Danish study, loop diuretics were associated with an increased risk of revision following primary THA, but there was no protective effect with thiazides [126].

\section{Conclusions}

To date, there is a limited understanding of how patient-related, biological factors affect the osseointegration of orthopedic implants. Similarly, the local and/or systemic effects of various classes of antiresorptive and bone anabolic medications are poorly understood. Our review of the published clinical literature highlights a number of important observations. Notably, based on evidence accumulating in osteoarthritis and osteoporosis research, we believe that there is a need to better recognize the phenotypical and genetic heterogeneity and host response in arthroplasty patients (Fig. 1). Likewise, interventions aiming to improve the osseointegration of hip and knee implants possibly differ depending on the joint, etiology of joint damage, and comorbid conditions. For example, young, posttraumatic arthroplasty patients may require different interventions than the obese, metabolic syndrome patients. Furthermore, it is important to distinguish systemic risk factors that would require systemic interventions and local risk factors that possibly require local interventions. More pre-clinical and clinical research remains to be done to identify effective interventions to improve osseointegration of orthopedic implants. Improvements can be achieved by pharmacological, molecular, and stem cell-based methods that biologically enhance bone healing around the implant. A firm understanding of the clinical parameters that complicate osseointegration will permit development of proper animal models that recapitulate the most prevalent clinical conditions with increased failure risk. This combination of clinical and translational studies offers the greatest opportunity to improve patient outcome. 


\section{Compliance with Ethical Standards}

Conflict of Interest Hilal Maradit Kremers, Eric A. Lewallen, and Andre J. van Wijnen declare that they have no conflict of interest.

David G. Lewallen reports personal fees, non-financial support, and others from Zimmer Biomet; personal fees, non-financial support, and others from Pipeline Mako Stryker and others from American Joint Replacement Registry; and personal fees from Accuitive and personal fees from Link, outside the submitted work. In addition, Dr. Lewallen has a patent Zimmer issued.

Human and Animal Rights and Informed Consent Among the cited articles where one of the authors of the current report was an author, local institutional review board approval was obtained and maintained for studies where human (or animal) subject research was performed.

\section{References}

Papers of particular interest, published recently, have been highlighted as:

- Of importance

1. Steiner C, Andrews R, Barrett M, Weiss A. HCUP projections: mobility/orthopedic procedures 2011 to 2012. US: Agency for Healthcare Research and Quality; 2012.

2. Kremers HM, Larson DR, Crowson CS, et al. Prevalence of total hip and knee replacement in the United States. Journal of Bone and Joint Surgery-American. 2015;97A(17):1386-97. A comprehensive epidemiological study describing the growing number of arthroplasty patients in the United States.

3. Santaguida PL, Hawker GA, Hudak PL, et al. Patient characteristics affecting the prognosis of total hip and knee joint arthroplasty: a systematic review. Can J Surg. 2008;51(6):428-36.

4. Lewallen EA, Riester SM, Bonin CA, et al. Biological strategies for improved osseointegration and osteoinduction of porous metal orthopedic implants. Tissue Eng Part B Rev. 2015;21(2):218-30. A comprehensive basic science review of biological strategies about osseointegration.

5. Gallo J, Goodman SB, Konttinen YT, Wimmer MA, Holinka M. Osteolysis around total knee arthroplasty: a review of pathogenetic mechanisms. Acta Biomater. 2013;9(9):8046-58.

6. Prokopetz JJ, Losina E, Bliss RL, Wright J, Baron JA, Katz JN. Risk factors for revision of primary total hip arthroplasty: a systematic review. BMC Musculoskelet Disord. 2012;13:251.

7. Khatod M, Cafri G, Namba RS, Inacio MCS, Paxton EW. Risk factors for total hip arthroplasty aseptic revision. J Arthroplasty. 2014;29(7):1412-7.

8. Namba RS, Cafri G, Khatod M, Inacio MCS, Brox TW, Paxton EW. Risk factors for total knee arthroplasty aseptic revision. J Arthroplasty. 2013;28(8):122-7.

9. Inacio MCS, Paxton EW, Ake C, Namba RS, Khatod M. Risk factors associated with total knee replacement failure in a large community based total joint replacement registry. Am J Epidemiol. 2011;173:S19-9.

10. Malchau H, Herberts P, Ahnfelt L. Prognosis of total hipreplacement in Sweden-follow-up of 92,675 operations performed 1978-1990. Acta Orthop Scand. 1993;64(5):497-506.

11. Julin J, Jamsen E, Puolakka T, Konttinen YT, Moilanen T. Younger age increases the risk of early prosthesis failure following primary total knee replacement for osteoarthritis. A follow-up study of 32,
019 total knee replacements in the Finnish Arthroplasty Register. Acta Orthop. 2010;81(4):413-9.

12. Kremers HM, Howard JL, Loechler Y, et al. Comparative long-term survivorship of uncemented acetabular components in revision total hip arthroplasty. J Bone Joint Surg Am. 2012;94(12):e82.

13. Kremers HM, Sierra RJ, Schleck CD, et al. Comparative survivorship of different tibial designs in primary total knee arthroplasty. J Bone Joint Surg Am. 2014;96(14):e121.

14. Roder C, Bach B, Berry DJ, Eggli S, Langenhahn R, Busato A. Obesity, age, sex, diagnosis, and fixation mode differently affect early cup failure in total hip arthroplasty: a matched case-control study of 4420 patients. J Bone Joint Surg Am. 2010;92(10):1954-63.

15. Teusink MJ, Callaghan KA, Klocke NF, Goetz DD, Callaghan JJ. Femoral remodeling around Charnley total hip arthroplasty is unpredictable. Clin Orthop Relat Res. 2013;471(12):3838-46.

16. Berry DJ, Harmsen WS, Cabanela ME, Morrey BF. Twenty-five-year survivorship of two thousand consecutive primary Charnley total hip replacements: factors affecting survivorship of acetabular and femoral components. J Bone Joint Surg Am. 2002;84-A(2):171-7.

17. Inacio MC, Ake CF, Paxton EW, et al. Sex and risk of hip implant failure: assessing total hip arthroplasty outcomes in the United States. Jama Intern Med. 2013;173(6):435-41.

18. Khosla S, Melton LJ, Riggs BL. The unitary model for estrogen deficiency and the pathogenesis of osteoporosis: is a revision needed? J Bone Miner Res. 2011;26(3):441-51.

19. Lavernia CJ, Villa JM. Does race affect outcomes in total joint arthroplasty? Clin Orthop Relat Res. 2015;473(11):3535-41.

20. Skinner J, Weinstein JN, Sporer SM, Wennberg JE. Racial, ethnic, and geographic disparities in rates of knee arthroplasty among Medicare patients. New Engl J Med. 2003;349(14):1350-9.

21. Cauley JA, Lui LY, Ensrud KE, et al. Bone mineral density and the risk of incident nonspinal fractures in black and white women. Jama-J Am Med Assoc. 2005;293(17):2102-8.

22. Kremers HM, Visscher SL, Kremers WK, Naessens JM, Lewallen DG. The effect of obesity on direct medical costs in total knee arthroplasty. J Bone Joint Surg Am. 2014;96(9):718-24.

23. Cherian JJ, Jauregui JJ, Banerjee S, Pierce T, Mont MA. What host factors affect aseptic loosening after THA and TKA? Clin Orthop Relat Res. 2015;473(8):2700-9.

24. Wagner ER, Kamath AF, Fruth KM, Harmsen WS, Berry DJ. Effect of body mass index on complications and reoperations after total hip arthroplasty. Journal of Bone and Joint Surgery-American Volume. 2016;98A(3):169-79.

25. Si HB, Zeng Y, Shen B, et al. The influence of body mass index on the outcomes of primary total knee arthroplasty. Knee Surg Sport Tr A. 2015;23(6):1824-32.

26. Zingg M, Miozzari HH, Fritschy D, Hoffmeyer P, Lubbeke A. Influence of body mass index on revision rates after primary total knee arthroplasty. Int Orthop. 2015.

27. Abdel MP, Bonadurer 3rd GF, Jennings MT, Hanssen AD. Increased aseptic tibial failures in patients with a BMI $>/=35$ and well-aligned total knee arthroplasties. J Arthroplast. 2015;30(12):2181-4.

28. Haverkamp D, Klinkenbijl MN, Somford MP, Albers GHR, van der Vis HM. Obesity in total hip arthroplasty - does it really matter? A meta-analysis Acta Orthop. 2011;82(4):417-22.

29. Johansson H, Kanis JA, Oden A, et al. A meta-analysis of the association of fracture risk and body mass index in women. Journal of bone and mineral research: the official journal of the American Society for Bone and Mineral Research. 2014;29(1):223-33.

30. Chen YH, Guo QS, Pan XH, Qin L, Zhang P. Smoking and impaired bone healing: will activation of cholinergic anti-inflammatory pathway be the bridge? Int Orthop. 2011;35(9):1267-70.

31. Fini M, Giavaresi G, Salamanna F, et al. Harmful lifestyles on orthopedic implantation surgery: a descriptive review on alcohol and tobacco use. J Bone Miner Metab. 2011;29(6):633-44. 
32. Teng S, Yi C, Krettek C, Jagodzinski M. Smoking and risk of prosthesis-related complications after total hip arthroplasty: a meta-analysis of cohort studies. PLoS One. 2015;10(4):e0125294.

33. Kremers HM, Kremers WK, Berry DJ, Lewallen DG. Social and behavioral factors in total knee and hip arthroplasty. J Arthroplasty. 2015;30(10):1852-4.

34. Hedlundh U, Fredin H. Patient characteristics in dislocations after primary total hip arthroplasty -60 patients compared with a control group. Acta Orthop Scand. 1995;66(3):225-8.

35. Espehaug B, Havelin LI, Engesaeter LB, Langeland N, Vollset SE. Patient-related risk factors for early revision of total hip replacements - a population register-based case-control study of 674 revised hips. Acta Orthop Scand. 1997;68(3):207-15.

36. Kanis JA, Johnell O, Oden A, et al. Smoking and fracture risk: a meta-analysis. Osteoporosis Int. 2005;16(2):155-62.

37. Kanis JA, Johansson H, Johnell O, et al. Alcohol intake as a risk factor for fracture. Osteoporosis Int. 2005;16(7):737-42.

38. Rud-Sorensen C, Pedersen AB, Johnsen SP, Riis AH, Overgaard S. Survival of primary total hip arthroplasty in rheumatoid arthritis patients Findings in 1,661 arthroplasties in 1,395 patients from the Danish Hip Arthroplasty Registry. Acta Orthop. 2010;81(1):60-5.

39. Ravi B, Escott B, Shah PS, et al. A systematic review and metaanalysis comparing complications following total joint arthroplasty for rheumatoid arthritis versus for osteoarthritis. Arthritis Rheum-Us. 2012;64(12):3839-49.

40. Zwartele R, Poll RG. Cemented total hip arthroplasty in rheumatoid arthritis. A systematic review of the literature. Hip Int. 2013;23(2):111-22.

41. Schrama JC, Fenstad AM, Dale H, et al. Increased risk of revision for infection in rheumatoid arthritis patients with total hip replacements. A study of 390,671 primary arthroplasties from the Nordic Arthroplasty Register Association. Acta Orthop. 2015;86(4):491-7.

42. Chougle A, Hemmady MV, Hodgkinson JP. Long-term survival of the acetabular component after total hip arthroplasty with cement in patients with developmental dysplasia of the hip. Journal of Bone and Joint Surgery-American Volume. 2006;88A(1):71-9.

43. Mabry TM, Prpa B, Haidukewych GJ, Harmsen WS, Berry DJ. Long-term results of total hip arthroplasty for femoral neck fracture nonunion. Journal of Bone and Joint Surgery-American Volume. 2004;86A(10):2263-7.

44. Abdel MP, von Roth P, Cross WW, Berry DJ, Trousdale RT, Lewallen DG. Total knee arthroplasty in patients with a prior tibial plateau fracture: a long-term report at 15 years. J Arthroplasty. 2015;30(12):2170-2

45. Dawson-Hughes B, Looker AC, Tosteson ANA, Johansson H, Kanis JA, Melton LJ. The potential impact of the National Osteoporosis Foundation guidance on treatment eligibility in the USA: an update in NHANES 2005-2008. Osteoporosis Int. 2012;23(3):811-20.

46. Geusens PP, van den Bergh JP. Osteoporosis and osteoarthritis: shared mechanisms and epidemiology. Curr Opin Rheumatol. 2016;28(2):97-103. Comprehensive review of current understanding of etiology of osteoarthritis and osteoporosis

47. Bruyere O, Cooper C, Arden N, et al. Can we identify patients with high risk of osteoarthritis progression who will respond to treatment? A focus on epidemiology and phenotype of osteoarthritis. Drugs Aging. 2015;32(3):179-87.

48. Herrero-Beaumont G, Roman-Blas JA, Largo R, Berenbaum F, Castaneda S. Bone mineral density and joint cartilage: four clinical settings of a complex relationship in osteoarthritis. Ann Rheum Dis. 2011;70(9):1523-5.

49. Zhang W, Likhodii S, Zhang Y, et al. Classification of osteoarthritis phenotypes by metabolomics analysis. BMJ Open. 2014;4(11): e006286.

50. Makinen TJ, Alm JJ, Laine H, Svedstrom E, Aro HT. The incidence of osteopenia and osteoporosis in women with hip osteoarthritis scheduled for cementless total joint replacement. Bone. 2007;40(4):1041-7.

51. Lingard EA, Mitchell SY, Francis RM, et al. The prevalence of osteoporosis in patients with severe hip and knee osteoarthritis awaiting joint arthroplasty. Age Ageing. 2010;39(2):234-9.

52. Glowacki J, Hurwitz S, Thornhill TS, Kelly M, LeBoff MS. Osteoporosis and vitamin-D deficiency among postmenopausal women with osteoarthritis undergoing total hip arthroplasty. Journal of Bone and Joint Surgery-American Volume. 2003;85A(12):2371-7.

53. Labuda A, Papaioannou A, Pritchard J, Kennedy C, DeBeer J, Adachi JD. Prevalence of osteoporosis in osteoarthritic patients undergoing total hip or total knee arthroplasty. Arch Phys Med Rehabil. 2008;89(12):2373-4.

54. Finnila S, Moritz N, Svedstro ME, Alm JJ, Aro HT. Increased migration of uncemented acetabular cups in female total hip arthroplasty patients with low systemic bone mineral density. Acta Orthop. 2016;87(1):48-54.

55. Wilkinson JM, Hamer AJ, Rogers A, Stockley I, Eastell R. Bone mineral density and biochemical markers of bone turnover in aseptic loosening after total hip arthroplasty. J Orthopaed Res. 2003;21(4):691-6

56. Schett G, Kleyer A, Perricone C, et al. Diabetes is an independent predictor for severe osteoarthritis results from a longitudinal cohort study. Diabetes Care. 2013;36(2):403-9.

57. Louati K, Vidal C, Berenbaum F, Sellam J. Association between diabetes mellitus and osteoarthritis: systematic literature review and meta-analysis. RMD Open. 2015;1(1):e00077.

58. Berenbaum F. Diabetes-induced osteoarthritis: from a new paradigm to a new phenotype. Ann Rheum Dis. 2011;70(8):1354-6. Overview of emerging evidence about diabetes-associated osteoarthritis.

59. Eymard F, Parsons C, Edwards MH, et al. Diabetes is a risk factor for knee osteoarthritis progression. Osteoarthritis Cartilage. 2015;23(6):851-9.

60. Shanbhogue VV, Mitchell DM, Rosen CJ, Bouxsein ML. Type 2 diabetes and the skeleton: new insights into sweet bones. Lancet Diabetes Endo. 2016;4(2):159-73.

61. Nielen JTH, de Vries F, Dagnelie PC, et al. Use of thiazolidinediones and the risk of elective hip or knee replacement: a population based case-control study. Brit J Clin Pharmaco. 2016;81(2):370-8.

62. Janghorbani M, Feskanich D, Willett WC, Hu F. Prospective study of diabetes and risk of hip fracture - the Nurses' Health Study. Diabetes Care. 2006;29(7):1573-8.

63. Meier C, Schwartz AV, Egger A, Lecka-Czernik B. Effects of diabetes drugs on the skeleton. Bone. 2016;82:93-100.

64. Srikanthan P, Crandall CJ, Miller-Martinez D, et al. Insulin resistance and bone strength: findings from the study of midlife in the United States. J Bone Miner Res. 2014;29(4):796-803.

65. Maradit Kremers H, Lewallen LW, Mabry TM, Berry DJ, Berbari EF, Osmon DR. Diabetes mellitus, hyperglycemia, hemoglobin $\mathrm{A} 1 \mathrm{C}$ and the risk of prosthetic joint infections in total hip and knee arthroplasty. J Arthroplast. 2015;30(3):439-43.

66. Hwang JS, Kim SJ, Bamne AB, Na YG, Kim TK. Do glycemic markers predict occurrence of complications after total knee arthroplasty in patients with diabetes? Clin Orthop Relat Res. 2015;473(5):1726-31

67. Lovecchio F, Beal M, Kwasny M, Manning D. Do patients with insulin-dependent and noninsulin-dependent diabetes have different risks for complications after arthroplasty? Clin Orthop Relat Res. 2014;472(11):3570-5.

68. Singh JA, Lewallen DG. Diabetes: a risk factor for poor functional outcome after total knee arthroplasty. PLoS One. 2013;8(11):e78991.

69. Adams AL, Paxton EW, Wang JQ, et al. Surgical outcomes of total knee replacement according to diabetes status and glycemic control, 2001 to 2009. J Bone Joint Surg Am. 2013;95(6):481-7. 
70. Robertson F, Geddes J, Ridley D, McLeod G, Cheng K. Patients with Type 2 diabetes mellitus have a worse functional outcome post knee arthroplasty: a matched cohort study. Knee. 2012;19(4):286-9.

71. Pedersen AB, Mehnert F, Johnsen SP, Sorensen HT. Risk of revision of a total hip replacement in patients with diabetes mellitus: a population-based follow up study. J Bone Joint Surg (Br). 2010;92(7):929-34.

72. Jamsen E, Peltola M, Eskelinen A, Lehto MUK. Comorbid diseases as predictors of survival of primary total hip and knee replacements: a nationwide register-based study of 96754 operations on patients with primary osteoarthritis. Ann Rheum Dis. 2013;72(12):1975-82.

73. Watts CD, Houdek MT, Wagner ER, Abdel MP, Taunton MJ. Insulin dependence increases the risk of failure after total knee arthroplasty in morbidly obese patients. J Arthroplasty. 2016;31(1):256-9.

74. de Munter W, van der Kraan PM, van den Berg WB, van Lent PL. High systemic levels of low-density lipoprotein cholesterol: fuel to the flames in inflammatory osteoarthritis? Rheumatology (Oxford). 2016;55(1):16-24.

75. Zhuo Q, Yang W, Chen JY, Wang Y. Metabolic syndrome meets osteoarthritis. Nat Rev Rheumatol. 2012;8(12):729-37.

76. Kluzek S, Newton JL, Arden NK. Is osteoarthritis a metabolic disorder? Br Med Bull. 2015;115(1):111-21.

77. Jungmann PM, Kraus MS, Alizai H, et al. Association of metabolic risk factors with cartilage degradation assessed by $\mathrm{T} 2$ relaxation time at the knee: data from the osteoarthritis initiative. Arthrit Care Res. 2013;65(12):1942-50.

78. Monira Hussain S, Wang Y, Cicuttini FM, et al. Incidence of total knee and hip replacement for osteoarthritis in relation to the metabolic syndrome and its components: a prospective cohort study. Semin Arthritis Rheum. 2014;43(4):429-36.

79. Visser AW, de Mutsert R, le Cessie S, et al. The relative contribution of mechanical stress and systemic processes in different types of osteoarthritis: the NEO study. Ann Rheum Dis. 2015;74(10):1842-7.

80. Gage MJ, Schwarzkopf R, Abrouk M, Slover JD. Impact of metabolic syndrome on perioperative complication rates after total joint arthroplasty surgery. J Arthroplast. 2014;29(9):1842-5.

81. Kawai M, de Paula FJA, Rosen CJ. New insights into osteoporosis: the bone-fat connection. J Intern Med. 2012;272(4):317-29.

82. Beck RT, Illingworth KD, Saleh KJ. Review of periprosthetic osteolysis in total joint arthroplasty: an emphasis on host factors and future directions. J Orthop Res. 2012;30(4):541-6.

83. MacInnes SJ, Del Vescovo E, Kiss-Toth E, et al. Genetic variation in inflammatory and bone turnover pathways and risk of osteolytic responses to prosthetic materials. J Orthopaed Res. 2015;33(2):193-8.

84. Gordon A, Greenfield EM, Eastell R, Kiss-Toth E, Wilkinson JM. Individual susceptibility to periprosthetic osteolysis is associated with altered patterns of innate immune gene expression in response to pro-inflammatory stimuli. J Orthopaed Res. 2010;28(9):1127-35.

85. Mrazek F, Gallo J, Arakelyan A, Kubistova Z, Petrek M. Single nucleotide polymorphisms in genes for cytokines interleukin (IL)2, IL-6 and TNFalpha influence severity of osteolysis after total hip arthroplasty. Tissue Antigens. 2008;71(4):331-2.

86. Jin X, Jones G, Cicuttini F, et al. Effect of vitamin D supplementation on tibial cartilage volume and knee pain among patients with symptomatic knee osteoarthritis: a randomized clinical trial. Jama. 2016;315(10):1005-13.

87. Bhandari M, Bajammal S, Guyatt GH, et al. Effect of bisphosphonates on periprosthetic bone mineral density after total joint arthroplasty. A meta-analysis. J Bone Joint Surg Am. 2005;87(2):293-301.

88. Prieto-Alhambra D, Javaid MK, Judge A, et al. Association between bisphosphonate use and implant survival after primary total arthroplasty of the knee or hip: population based retrospective cohort study. Brit Med J. Dec 6 2011;343.
89. Prieto-Alhambra D, Javaid MK, Judge A, et al. Bisphosphonate use is associated with reduced revisions of lower limb joint (knee or hip) arthroplasty: a population-based cohort study. Osteoporosis Int. 2011;22:101-2.

90. Prieto-Alhambra D, Lalmohamed A, Abrahamsen B, et al. Oral bisphosphonate use and total knee/hip implant survival validation of results in an external population-based cohort. Arthritis Rheumatol. 2014;66(11):3233-40.

91. Thillemann TM, Pedersen AB, Mehnert F, Johnsen SP, Soballe K. Postoperative use of bisphosphonates and risk of revision after primary total hip arthroplasty: a nationwide population-based study. Bone. 2010;46(4):946-51.

92. Khatod M, Inacio MC, Dell RM, Bini SA, Paxton EW, Namba RS. Association of bisphosphonate use and risk of revision after THA: outcomes from a US Total Joint Replacement Registry. Clin Orthop Relat Res. 2015;473(11):3412-20.

93. Namba RS, Inacio MC, Cheetham TC, Dell RM, Paxton EW, Khatod MX. Lower total knee arthroplasty revision risk associated with bisphosphonate use, even in patients with normal bone density. J Arthroplast. 2016;31(2):537-41.

94. Teng S, Yi C, Krettek C, Jagodzinski M. Bisphosphonate use and risk of implant revision after total hip/knee arthroplasty: a metaanalysis of observational studies. PLoS One. 2015;10(10): e0139927. Meta-analysis supporting long-term effects of bisphosphonates in arthroplasty patients.

95. Alhambra DP, Lalmohamed A, Abrahamsen B, et al. Bisphosphonate use and improved implant survival: a nationwide cohort study. Rheumatology (Oxford). 2013;52:41-1.

96. Lin T, Yan SG, Cai XZ, Ying ZM. Bisphosphonates for periprosthetic bone loss after joint arthroplasty: a meta-analysis of 14 randomized controlled trials. Osteoporos Int. 2012;23(6):1823-34.

97. Zhao XY, Hu DC, Qin J, Mohanan R, Chen LB. Effect of bisphosphonates in preventing femoral periprosthetic bone resorption after primary cementless total hip arthroplasty: a meta-analysis. J Orthop Surg Res. 2015;10.

98. Solomon DH, Hochberg MC, Mogun H, Schneeweiss S. The relation between bisphosphonate use and non-union of fractures of the humerus in older adults. Osteoporosis Int. 2009;20(6):895-901.

99. Chen BL, Xie DH, Zheng ZM, et al. Comparison of the effects of alendronate sodium and calcitonin on bone-prosthesis osseointegration in osteoporotic rats. Osteoporos Int. 2011;22(1):265-70.

100. Prieto-Alhambra D, Javaid MK, Judge A, et al. Hormone replacement therapy and mid-term implant survival following knee or hip arthroplasty for osteoarthritis: a population-based cohort study. Ann Rheum Dis. 2015;74(3):557-63.

101. Komm BS, Chines AA. An update on selective estrogen receptor modulators for the prevention and treatment of osteoporosis. Maturitas. 2012;71(3):221-6.

102. Aghajanian $\mathrm{P}$, Hall S, Wongworawat MD, Mohan S. The roles and mechanisms of actions of vitamin $\mathrm{C}$ in bone: new developments. Journal of bone and mineral research: the official journal of the American Society for Bone and Mineral Research. 2015;30(11):1945-55.

103. Finck H, Hart AR, Jennings A, Welch AA. Is there a role for vitamin $\mathrm{C}$ in preventing osteoporosis and fractures? A review of the potential underlying mechanisms and current epidemiological evidence. Nutr Res Rev. 2014;27(2):268-83.

104. Bhattacharyya T, Levin R, Vrahas MS, Solomon DH. Nonsteroidal antiinflammatory drugs and nonunion of humeral shaft fractures. Arthrit Rheum-Arthr. 2005;53(3):364-7.

105. Geusens P, Emans PJ, de Jong JJA, van den Bergh J. NSAIDs and fracture healing. Curr Opin Rheumatol. 2013;25(4):524-31.

106. Malik MH, Gray J, Kay PR. Early aseptic loosening of cemented total hip arthroplasty: the influence of non-steroidal anti-inflammatory drugs and smoking. Int Orthop. 2004;28(4):211-3.

107. Nizam I, Kohan L, Field C, Kerr D. Do nonsteroidal antiinflammatory drugs cause endoprosthetic loosening? Mid- to 
long-term follow-up of 100 total hip arthroplasties after local NSAID infiltration. Biomed Res Int. 2015.

108. Persson PE, Nilsson OS, Berggren AM. Do non-steroidal anti-inflammatory drugs cause endoprosthetic loosening? A 10-year follow-up of a randomized trial on ibuprofen for prevention of heterotopic ossification after hip arthroplasty. Acta Orthop. 2005;76(6):735-40.

109. Meunier A, Aspenberg P, Good L. Celecoxib does not appear to affect prosthesis fixation in total knee replacement: a randomized study using radiostereometry in 50 patients. Acta Orthop. 2009;80(1):46-50.

110. Thrailkill KM, Lumpkin CK, Bunn RC, Kemp SF, Fowlkes JL. Is insulin an anabolic agent in bone? Dissecting the diabetic bone for clues. Am J Physiol-Endoc M. 2005;289(5):E735-45.

111. Zhu ZN, Jiang YF, Ding T. Risk of fracture with thiazolidinediones: an updated meta-analysis of randomized clinical trials. Bone. 2014;68:115-23.

112. Bauer DC, Mundy GR, Jamal SA, et al. Use of statins and fracture: results of 4 prospective studies and cumulative meta-analysis of observational studies and controlled trials. Arch Intern Med. 2004;164(2):146-52.

113. Chan KA, Andrade SE, Boles M, et al. Inhibitors of hydroxymethylglutaryl-coenzyme A reductase and risk of fracture among older women. Lancet. 2000;355(9222):2185-8.

114. Adams AL, Shi JXM, Reynolds K, et al. Statins and hip fracture risk in men: a population-based case-control study. Ann Epidemiol. 2015;25(11):844-8.

115. Pena JM, Aspberg S, MacFadyen J, Glynn RJ, Solomon DH, Ridker PM. Statin therapy and risk of fracture: results from the JUPITER randomized clinical trial. Jama Intern Med. 2015;175(2):171-7.

116. Reid IR, Hague W, Emberson J, et al. Effect of pravastatin on frequency of fracture in the LIPID study: secondary analysis of a randomised controlled trial. Lancet. 2001;357(9255):509-12.
117. Toh S, Hernandez-Diaz S. Statins and fracture risk. A systematic review. Pharmacoepidem Dr S. 2007;16(6):627-40.

118. Thillemann TM, Pedersen AB, Mehnert F, Johnsen SP, Soballe K. The risk of revision after primary total hip arthroplasty among statin users: a nationwide population-based nested case-control study. J Bone Joint Surg Am. 2010;92(5):1063-72.

119. Lubbeke A, Garavaglia G, Rothman KJ, et al. Statins may reduce femoral osteolysis in patients with total hip arthroplasty. J Orthopaed Res. 2013;31(5):814-20.

120. Goodman SM. Rheumatoid arthritis: perioperative management of biologics and DMARDs. Semin Arthritis Rheum. 2015;44(6):627-32.

121. Aaltonen KJ, Virkki LM, Jamsen E, et al. Do biologic drugs affect the need for and outcome of joint replacements in patients with rheumatoid arthritis? A register-based study. Semin Arthritis Rheum. 2013;43(1):55-62.

122. Ray WA, Griffin MR, Schaffner W, Baugh DK, Melton LJ. Psychotropic drug use and the risk of hip fracture. New Engl J Med. 1987;316(7):363-9.

123. Lanteigne A, Sheu YH, Sturmer T, et al. Serotonin-norepinephrine reuptake inhibitor and selective serotonin reuptake inhibitor use and risk of fractures: a new-user cohort study among US adults aged 50 years and older. CNS Drugs. 2015;29(3):245-52.

124. Solomon DH, Ruppert K, Zhao Z, et al. Bone mineral density changes among women initiating blood pressure lowering drugs: a SWAN cohort study. Osteoporosis Int. 2016;27(3):1181-9.

125. Ray WA, Griffin MR, Downey W, Melton LJ. Long-term use of thiazide diuretics and risk of hip fracture. Lancet. 1989;1(8640):687-90.

126. Thillemann TM, Pedersen AB, Mehnert F, Johnsen SP, Soballe K. Use of diuretics and risk of implant failure after primary total hip arthroplasty: a nationwide population-based study. Bone. 2009;45(3):499-504. 